\title{
Risk factors for interstitial lung disease induced by gemcitabine plus albumin- bound paclitaxel therapy in pancreatic ductal adenocarcinoma patients
}

Rikako Ueda ${ }^{1 *}$, Naho Yamamoto ${ }^{1}$, Yuki Hori ${ }^{1}$, Kouji Yoshida ${ }^{1}$, Koushiro Ohtsubo ${ }^{2}$, Takeshi Terashima ${ }^{3}$,

Tsutomu Shimada ${ }^{1}$ and Yoshimichi Sai ${ }^{1}$

\begin{abstract}
Background: Gemcitabine plus nab-paclitaxel (GnP) therapy is used for unresectable pancreatic ductal adenocarcinoma, but may cause interstitial lung disease (ILD) as a serious side effect. However, the risk factors for ILD in patients receiving GnP therapy are not well established. Here, we retrospectively investigated the incidence of GnP-induced ILD in pancreatic ductal adenocarcinoma patients, and the risk factors.

Methods: We investigated the patients' background, laboratory data, previous treatment history, concomitant medications, number of doses of GnP, cumulative dosage and administration period, and occurrence of side effects.

Results: Of the 105 patients included in this study, ILD occurred in 10 (9.5\%). Patients with ILD had a significantly higher frequency of concomitant treatment with Kampo medicines, especially goshajinkigan, which is considered to help prevent chemotherapy-induced peripheral neuropathy (CIPN) (odds ratio: 11.5, 95\% confidence interval: 2.6749.38). No significant differences were observed in other clinical characteristics. Notably, the severity of CIPN in patients who used goshajinkigan for prevention was not significantly different from that in patients who did not use goshajinkigan in this study.
\end{abstract}

Conclusions: These results suggest that administration of goshajinkigan to patients receiving GnP therapy for prevention of CIPN may need to be reconsidered.

Keywords: Pancreatic ductal adenocarcinoma, Interstitial lung disease, Gemcitabine plus nab-paclitaxel therapy, Risk factor, Goshajinkigan

\section{Introduction}

Gemcitabine (GEM) plus nab-paclitaxel (nabPTX) (GnP) therapy has been widely used in Japan as chemotherapy for unresectable metastatic pancreatic ductal adenocarcinoma (PDAC) since it was approved in December 2014. In the Clinical Practice Guideline for Pancreatic

\footnotetext{
*Correspondence: rikakko88@staff.kanazawa-u.ac.jp

'Department of Hospital Pharmacy, University Hospital, Kanazawa University, 13-1 Takaramachi, Kanazawa, Ishikawa, Japan

Full list of author information is available at the end of the article
}

Cancer 2019, GnP therapy is recommended as a firstline treatment along with FOLFIRINOX therapy (oxaliplatin + irinotecan + fluorouracil + levofolinate calcium) for locally advanced unresectable or metastatic PDAC [1].

However, interstitial lung disease (ILD) is a serious side effect of many anticancer agents, including GEM, nabPTX, and especially GnP [2], and is associated with high mortality. In a phase III international multicenter study in PDAC patients, the incidence of ILD was $1 \%$ in

C C The Author(s). 2021 Open Access This article is licensed under a Creative Commons Attribution 4.0 International License, which permits use, sharing, adaptation, distribution and reproduction in any medium or format, as long as you give appropriate credit to the original author(s) and the source, provide a link to the Creative Commons licence, and indicate if changes were made. The images or other third party material in this article are included in the article's Creative Commons licence, unless indicated otherwise in a credit line to the material. If material is not included in the article's Creative Commons licence and your intended use is not permitted by statutory regulation or exceeds the permitted use, you will need to obtain permission directly from the copyright holder. To view a copy of this licence, visit http://creativecommons.org/licenses/by/4.0/ The Creative Commons Public Domain Dedication waiver (http://creativecommons.org/publicdomain/zero/1.0/) applies to the data made available in this article, unless otherwise stated in a credit line to the data. 
the GEM group and $4 \%$ in the nabPTX combination group [3]. According to the Japan Respiratory Society's Guide for Diagnosis and Treatment of Drug-induced Pulmonary Disorders, non-specific risk factors for ILD include age 60 years or older, presence of existing lung disease (particularly interstitial pneumonia, pulmonary fibrosis), post-pulmonary surgery, deterioration of respiratory function, high-concentration oxygen administration, lung irradiation, multidrug therapy with anticancer drugs, heart disease, and renal disorders [4]. Specific risk factors for GEM-related ILD include elderly status, smoking, history of chemotherapy, advanced cancer stage, history of lung disease or lung cancer, and prior thoracic radiotherapy [5-7]. In addition, poor performance status has been reported as a risk factor for ILD in patients receiving several anticancer drugs $[8,9]$. As for GnP therapy, Takeda et al. reported that ABO blood type $\mathrm{B}$ was an independent risk factor for ILD in PDAC patients [10]. Irie et al. found that the median age of GnP-treated patients with ILD was significantly higher than that of GnP-treated patients without ILD [11]. However, the risk factors for ILD in patients receiving $\mathrm{GnP}$ therapy have not yet been thoroughly investigated.

Therefore, we aimed to clarify the incidence of ILD in PDAC patients receiving GnP therapy, and to investigate the risk factors, in order to provide safer chemotherapy.

\section{Materials \& methods}

\section{Patients}

The subjects were patients who underwent GnP therapy for locally advanced unresectable or metastatic PDAC at Kanazawa University Hospital from February 2015 to March 2019. Patients who received GnP only on day 1 were excluded. A standard 4-week course consisted of nab-PTX $125 \mathrm{mg} / \mathrm{m}^{2}$, GEM $1000 \mathrm{mg} / \mathrm{m}^{2}$ administered on days 1,8 and 15 , with a drug holiday on day 22 .

\section{Subjects for analysis}

From the electronic medical records system, we collected data on pretreatment clinical characteristics, including age, gender, performance status (Eastern Cooperative Oncology Group), chemotherapy history, putative risk factors for ILD (history of lung disease, lung metastasis, lung surgery, thoracic radiotherapy, smoking, heart disease, and renal function), concomitant medications at the initiation of GnP treatment (nonsteroidal anti-inflammatory agents (NSAIDs), proton pump inhibitors (PPIs), Kampo medicines, and pregabalin), administration period of concomitant medications, number of $\mathrm{GnP}$ doses, cumulative dosage and administration period, severity and time of onset of ILD, KL-6 level at the onset, clinical outcome, and the severity of chemotherapy-induced peripheral neuropathy (CIPN). Regarding concomitant drugs, we targeted drugs for which ILD is documented as a serious side effect, or that have been reported to cause ILD, and that were regularly used for 1 week or more, since onset of ILD is reported to occur at 1 to 6 weeks after the start of drug administration [4].

\section{Evaluation method}

The severity of ILD and CIPN was evaluated based on the National Cancer Institute Common Terminology Criteria for Adverse Events (CTCAE) ver.5.0. ILD was diagnosed based on a comprehensive evaluation of the patients' clinical course, physical findings (cough, respiratory distress, fever, and decreased $\mathrm{SpO} 2)$, X-ray findings, computed tomography findings (CT) and laboratory data (serum lactate dehydrogenase, $\mathrm{C}$-reactive protein, KL-6, or surfactant proteins A or D). For differential diagnosis, absence of infection was confirmed by sputum and blood culture and serodiagnostic tests (1,3$\beta$-d-glucan, cytomegalovirus antigenemia, or procalcitonin), or lack of response to antibiotics, in order to rule out infection or other pneumonia. Treatment of ILD was determined in consultation with a pulmonologist. The severity of CIPN was evaluated based on the medical records of physicians, nurses, and pharmacists at the time of discontinuation of $\mathrm{GnP}$ therapy or at the time of cutoff. If CIPN had developed before the initiation of GnP therapy, the onset of CIPN was defined as the time when CIPN worsened after the initiation of $\mathrm{GnP}$ therapy.

\section{Statistical analysis}

To examine risk factors, univariate analysis was performed for each factor using the Mann-Whitney $U$-test or Fisher's exact test. $P<0.05$ was considered statistically significant. The analysis was performed using SPSS ver. 24 statistical software (SPSS Co., Ltd., Tokyo).

\section{Ethics}

This study was conducted with the approval of the Kanazawa University Medical Ethics Review Committee in compliance with the "Ethical Guidelines for Medical Research for Humans" (Clinical Trial No. 2018-151).

\section{Results}

\section{Patients' characteristics}

One hundred and seven patients who were treated with $\mathrm{GnP}$ therapy were registered. At the time of the data cutoff, 10 patients were still on treatment. Two patients were excluded because they were clinically diagnosed with progressive disease (PD) after a single dose, so the therapy was discontinued. Of the remaining 105 patients, 71 were males and 34 were females. The median age was 65 years. The number of patients receiving firstline treatment was 56, and the number receiving 
second-line or later treatment was 49. Prior treatment included modified FOLFIRINOX, S-1, GEM, and erlotinib. The median duration of treatment was 101 days and the median number of doses was 8 (Table 1 ).

\section{Concomitant medications at the initiation of treatment} Concomitant medications at the initiation of GnP therapy were PPIs in 80 patients (76\%), NSAIDs in 31 patients (30\%), Kampo medicines in 30 patients (29\%), and pregabalin in 8 patients $(8 \%)$. Some patients were using multiple drugs. Among the Kampo medicines, goshajinkigan (GJG), prescribed to prevent exacerbation of CIPN, was the most common (23 people, 22\%) (Table 2).

\section{Frequency of occurrence of ILD}

Of the 105 patients who received GnP, 10 (9.5\%) developed ILD, with 5 Grade 1 (4.8\%), 2 Grade 2 (1.9\%), and 3 Grade 3 or higher $(2.9 \%)$. The median period from initiation to onset was 79 days and the median number of cumulative doses was 8 . After the ILD onset, GnP therapy was discontinued in all cases, and the symptom improved in response to steroid therapy in all patients with Grade 2 or more, and without treatment in the Grade 1 patients (Table 1, Fig. 1).

\section{Risk factors for developing ILD}

To identify risk factors related to GnP-induced ILD, univariate analysis was performed using patient background factors and the presence or absence of ILD. GnPinduced ILD was significantly associated with the use of Kampo medicines, especially GJG (odds ratio: 11.5, 95\% confidence interval (CI): 2.67-49.38). Other patient background factors were not significantly associated with the development of ILD (Table 3).

\section{Demographics of patients with ILD}

Demographics of the 10 patients who developed ILD are summarized in Table 4. Age was 60 years or older except for one patient, and there was no consistency in the number of $\mathrm{GnP}$ administrations and the date of onset. One of the 10 cases had a history of lung disease. In addition, 4 cases had a history of treatment with modified FOLFIRINOX as the first-line chemotherapy. Six cases showed increased KL-6 (>500 U / mL) at the onset. Seven of 10 patients received GJG before the initiation of $\mathrm{GnP}$ treatment. There was no association between the duration of administration of GJG and the severity of $\operatorname{ILD}(P=0.324)$.

Table 1 Patients' characteristics

\begin{tabular}{|c|c|}
\hline & $n=105$ \\
\hline Age (years) & $65(37-79)^{\mathrm{a}}$ \\
\hline Gender (male/female), n (\%) & $71(68 \%) / 34(32 \%)$ \\
\hline Performance status $0, \mathrm{n}(\%)$ & $38(36 \%)$ \\
\hline $1, \mathrm{n}(\%)$ & $63(60 \%)$ \\
\hline $2, n(\%)$ & $4(4 \%)$ \\
\hline Line of treatment 1st line, $\mathrm{n}(\%)$ & $56(53 \%)$ \\
\hline 2nd line or later, $\mathrm{n}(\%)$ & $49(47 \%)$ \\
\hline Presence of lung disease, $\mathrm{n}(\%)$ & $9(9 \%)$ \\
\hline Presence of lung metastasis, $\mathrm{n}(\%)$ & $12(11 \%)$ \\
\hline History of pulmonary surgery, n (\%) & $0(0 \%)$ \\
\hline History of lung irradiation, n (\%) & $3(3 \%)$ \\
\hline Smoker, n (\%) & $55(52 \%)$ \\
\hline Presence of heart disease, $\mathrm{n}(\%)$ & $20(19 \%)$ \\
\hline GnP number of doses (time) & $8(2-63)^{a}$ \\
\hline $\mathrm{GnP}$ administration period (days) & $101(7-931)^{\mathrm{a}}$ \\
\hline GEM cumulative dosage (mg) & $12,050(2400-88,200+)^{a}$ \\
\hline nabPTX cumulative dosage $(\mathrm{mg})$ & $1520(360-7364+)^{a}$ \\
\hline ILD frequency, n (\%) & $10(9.5 \%)$ \\
\hline Period from initiation of treatment to onset (days) & $79(34-202)^{a}$ \\
\hline Cumulative number of doses of GnP (time) & $8(3-28)^{a}$ \\
\hline
\end{tabular}

GEM and nabPTX cumulative dosage include patients whose treatment is ongoing GnP Gemcitabine (GEM) + nab-paclitaxel (nab-PTX) therapy, ILD Interstitial lung disease ${ }^{a}$ Median (minimum-maximum) 
Table 2 Concomitant medications at the initiation of treatment

\begin{tabular}{|c|c|c|}
\hline & Patients & Percentage of all cases (\%) \\
\hline \multicolumn{3}{|l|}{ PPI } \\
\hline Rabeprazole & 38 & 36 \\
\hline Esomeprazole & 23 & 22 \\
\hline Vonoprazan & 15 & 14 \\
\hline Omeprazole & 4 & 4 \\
\hline \multicolumn{3}{|l|}{ NSAIDs } \\
\hline Loxoprofen & 17 & 16 \\
\hline Celecoxib & 7 & 7 \\
\hline Naproxen & 5 & 5 \\
\hline Meloxicam & 1 & 1 \\
\hline Tiaramide & 1 & 1 \\
\hline \multicolumn{3}{|l|}{ Kampo medicines } \\
\hline Goshajinkigan & 23 & 22 \\
\hline Daikentyuto & 3 & 3 \\
\hline Rikkunshito & 2 & 2 \\
\hline Hangeshashinto & 2 & 2 \\
\hline Ninjinyoeito & 1 & 1 \\
\hline Juzentaihoto & 1 & 1 \\
\hline Kakkonto & 1 & 1 \\
\hline Bukuryoingohangeshashinto & 1 & 1 \\
\hline \multicolumn{3}{|l|}{ Others } \\
\hline Pregabalin & 8 & 8 \\
\hline
\end{tabular}

PPI Proton pump inhibitor, NSAIDs Non-steroidal anti-inflammatory drugs

\section{Association between GJG preventive administration and CIPN severity}

The incidence of CIPN among all cases and the association of CIPN severity with GJG preventive administration were evaluated. Among the patients receiving GnP, $72(69 \%)$ developed CIPN, and the severity was Grade 1 in 41 (39\%), Grade 2 in 24 (23\%), and Grade 3 in 7 (7\%). As the background of patients who be onset CIPN, there was no difference in age, sex, nabPTX cumulative dosage, the pretreatment history of oxaliplatin, and the history of CIPN at the initiation of GnP therapy between with and without GJG. Also, there was no difference in the use of pregabalin between with and without GJG. GJG administration appeared to have no protective effect against development of CIPN (Table 5).

\section{Discussion}

In this study, we investigated the incidence of ILD in PDAC patients receiving GnP therapy at our hospital. In the phase III international multicenter study of GnP therapy, the frequency of ILD was $4.0 \%(17 / 421)$ and the median period to develop ILD from initiation was 86 days [3]. Similarly, Takeda et al. reported that the incidence of ILD was $2.2 \%(20 / 910)$ in the PDAC patients receiving $\mathrm{GnP}$ therapy, and the median time to onset of ILD was 80 days [10]. On the other hand, Irie et al. observed a higher frequency of ILD in a small group of PDAC patients given GnP therapy $(18.9 \%, 7 / 37)$, and reported that the severity of ILD was mild, except for one patient, who recovered with steroid therapy [11]. In our study, the incidence of ILD was 9.5\% (10/105), and the median period to ILD onset was 79 days. Furthermore,

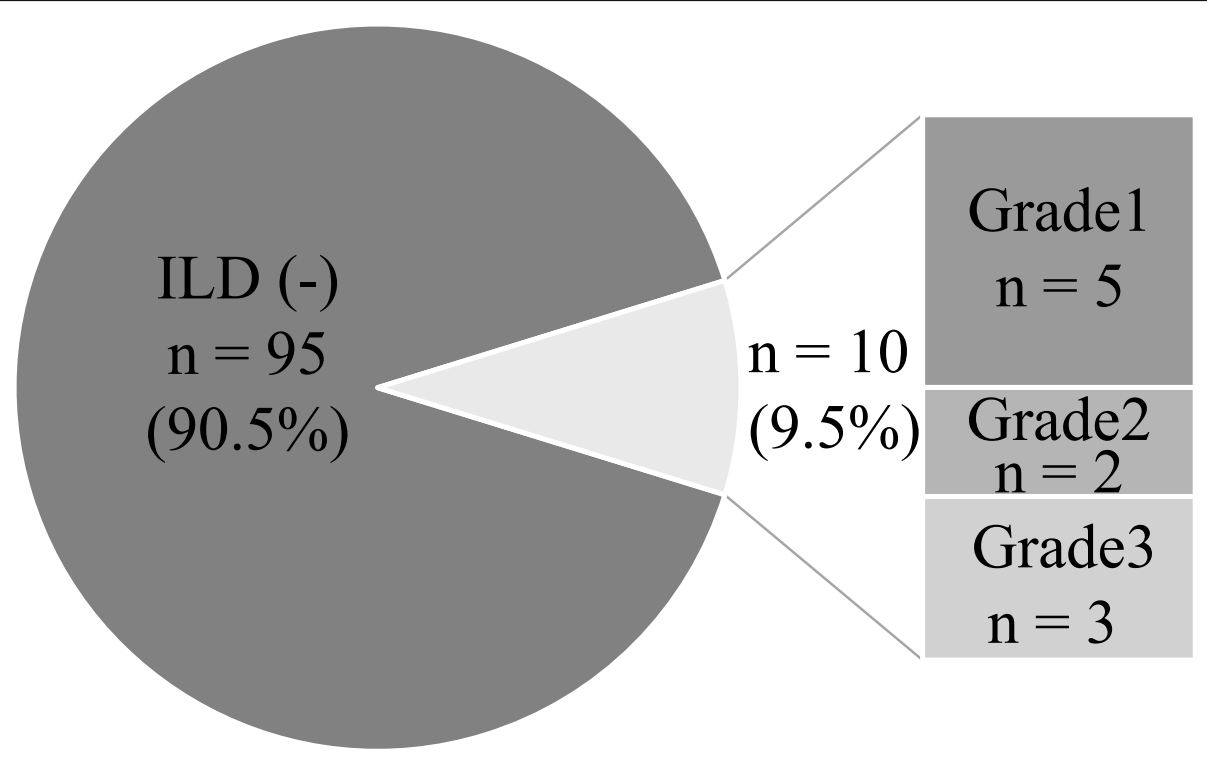

Fig. 1 Frequency and grade of interstitial lung disease in patients receiving gemcitabine plus albumin-bound paclitaxel therapy in this study 
Table 3 Risk factors for developing ILD

\begin{tabular}{|c|c|c|c|c|c|}
\hline & $\begin{array}{l}\text { ILD (+) } \\
\mathrm{n}=10\end{array}$ & $\begin{array}{l}\text { ILD (-) } \\
n=95\end{array}$ & $P$ & Odds ratio & $95 \% \mathrm{Cl}$ \\
\hline Age (years) & $70(57-79)^{c}$ & $66(37-79)^{c}$ & $0.127^{\mathrm{a}}$ & & \\
\hline Gender (male/female) & $5 / 5$ & $66 / 29$ & $0.287^{\mathrm{b}}$ & & \\
\hline GnP number of doses (time) & $8(3-28)^{c}$ & $9(2-63)^{c}$ & $0.562^{\mathrm{a}}$ & & \\
\hline GnP administration period (days) & $67(16-289)^{c}$ & $108(7-931)^{c}$ & $0.342^{\mathrm{a}}$ & & \\
\hline Performance status $0, \mathrm{n}(\%)$ & $1(10 \%)$ & $37(39 \%)$ & $0.129^{\mathrm{a}}$ & & \\
\hline $1, n(\%)$ & $9(90 \%)$ & $54(57 \%)$ & & & \\
\hline $2, n(\%)$ & $0(0 \%)$ & $4(4 \%)$ & & & \\
\hline History of chemotherapy (+/-) & $4 / 6$ & $45 / 50$ & $0.748^{\mathrm{b}}$ & & \\
\hline History of lung disease (+/-) & $1 / 9$ & $8 / 87$ & $1.000^{\mathrm{b}}$ & & \\
\hline Lung metastasis (+/-) & $1 / 9$ & $11 / 84$ & $1.000^{\mathrm{b}}$ & & \\
\hline Lung irradiation (+/-) & $0 / 10$ & $3 / 92$ & $1.000^{\mathrm{b}}$ & & \\
\hline Smoker (+/-) & $4 / 6$ & $51 / 44$ & $0.513^{b}$ & & \\
\hline Heart disease (+/-) & $2 / 8$ & $18 / 77$ & $1.000^{\mathrm{b}}$ & & \\
\hline $\mathrm{Scr}(\mathrm{mg} / \mathrm{dL})$ & $0.62(0.47-0.61)^{c}$ & $0.61(0.33-1.38)^{c}$ & $0.823^{\mathrm{a}}$ & & \\
\hline NSAIDs $(+/-)$ & $3 / 7$ & $28 / 67$ & $1.000^{\mathrm{b}}$ & & \\
\hline PPI (+/-) & $9 / 1$ & $71 / 24$ & $0.445^{b}$ & & \\
\hline Kampo medicines (+/-) & $7 / 3$ & $23 / 72$ & $0.005^{b}$ & & \\
\hline Goshajinkigan (+/-) & $7 / 3$ & $16 / 79$ & $0.001^{\mathrm{b}}$ & 11.5 & $2.67-49.38$ \\
\hline Pregabalin (+/-) & $2 / 8$ & $6 / 89$ & $0.168^{b}$ & & \\
\hline
\end{tabular}

GnP Gemcitabine (GEM) + nab-paclitaxel (nab-PTX) therapy, Scr Serum creatinine, NSAIDs Non-steroidal anti-inflammatory drugs, PPI Proton pump inhibitor, CI Confidence interval

${ }^{\mathrm{a}}$ Mann-Whitney $U$-test, ${ }^{\mathrm{b}}$ Fisher's exact test

cMedian (minimum-maximum)

Table 4 Demographics of the 10 patients who developed GnP-induced ILD

\begin{tabular}{|c|c|c|c|c|c|c|c|c|c|c|c|}
\hline & Age & Gender & $\begin{array}{l}\text { GnP } \\
\text { number of } \\
\text { doses }\end{array}$ & $\begin{array}{l}\text { Date of } \\
\text { onset }\end{array}$ & $\begin{array}{l}\text { History of } \\
\text { lung disease }\end{array}$ & $\begin{array}{l}\text { History of } \\
\text { chemotherapy }\end{array}$ & $\begin{array}{l}\text { KL- } 6 \text { at } \\
\text { onset }\end{array}$ & Treatment & Grade & $\begin{array}{l}\text { Concomitant } \\
\text { medications }\end{array}$ & $\begin{array}{l}\text { Duration of } \\
\text { administration of } \\
\text { GJG }\end{array}$ \\
\hline 1 & 69 & $M$ & 11 & 108 & COPD & mFFX 4C & 287 & $\mathrm{mPSL}+\mathrm{PSL}$ & 3 & GJG, RZ & 50 \\
\hline 2 & 68 & M & 28 & 302 & No & No & 192 & No & 1 & GJG & 134 \\
\hline 3 & 57 & $F$ & 6 & 54 & No & mFFX 4C & 527 & No & 1 & $E Z, L P$ & - \\
\hline 4 & 79 & $\mathrm{~F}$ & 4 & 43 & No & No & 3359 & No & 1 & GJG, RZ & 43 \\
\hline 5 & 70 & M & 12 & 162 & No & mFFX $6 C$ & 1822 & No & 1 & GJG, RZ & 252 \\
\hline 6 & 64 & $\mathrm{~F}$ & 6 & 65 & No & No & 578 & PSL & 3 & $\mathrm{RZ}$ & - \\
\hline 7 & 72 & F & 8 & 80 & No & No & 6342 & mPSL+PSL & 3 & $R Z$, LP & - \\
\hline 8 & 70 & M & 3 & 34 & No & mFFX $29 C$ & 293 & mPSL+PSL & 2 & GJG, RZ & 39 \\
\hline 9 & 79 & $F$ & 8 & 77 & No & No & 899 & mPSL+PSL & 2 & GJG, RZ & 77 \\
\hline 10 & 65 & M & 8 & 139 & No & No & 409 & No & 1 & GJG, NX, RZ & 139 \\
\hline
\end{tabular}

mFFX consists of oxaliplatin $85 \mathrm{mg} / \mathrm{m}^{2}$, leucovorin $200 \mathrm{mg} / \mathrm{m}^{2}$, irinotecan $150 \mathrm{mg} / \mathrm{m}^{2}$, and continuous intravenous infusion of 5 -FU at $2400 \mathrm{mg} / \mathrm{m}^{2}$, administered every 2 weeks. mPSL was administered at $0.5-1 \mathrm{~g} /$ day for 3 days, and PSL was administered at $0.5-1 \mathrm{mg} / \mathrm{kg} /$ day and the doses were gradually reduced over the clinical course. GJG was administered at $2.5 \mathrm{~g}$ three times daily. RZ was administered at $10 \mathrm{mg}$ once daily. EZ was administered at $20 \mathrm{mg}$ once daily. LP was administered at $60 \mathrm{mg}$ three times daily. NX was administered at $100 \mathrm{mg}$ three times daily mFFX Modified FOLFIRINOX therapy, mPSL Methylprednisolone, PSL Prednisolone, GJG Goshajinkigan, RZ Rabeprazole Na, EZ Esomeprazole, LP Loxoprofen Na, NX Naproxen 
Table 5 Association between goshajinkigan preventive administration and CIPN severity

\begin{tabular}{|c|c|c|c|}
\hline$n=105$ & $\begin{array}{l}\text { GJG (+) } \\
n=23\end{array}$ & $\begin{array}{l}\text { GJG (-) } \\
n=82\end{array}$ & $P$ \\
\hline Age (years) & $70(57-79)^{c}$ & $66(37-79)^{c}$ & $0.535^{\mathrm{a}}$ \\
\hline Gender (male/female) & $16 / 7$ & $55 / 27$ & $0.822^{\mathrm{b}}$ \\
\hline nabPTX cumulative dosage (mg) & $1112(400-7364)^{c}$ & $1589(360-7226)^{c}$ & $0.139^{\mathrm{a}}$ \\
\hline Pretreatment history of oxaliplatin, n (\%) & $8(35 \%)$ & $35(43 \%)$ & $0.496^{\mathrm{b}}$ \\
\hline Oxaliplatin cumulative dosage (mg) & $941(510-4399)^{c}$ & $1040(100-4405)^{c}$ & $0.679^{a}$ \\
\hline History of CIPN at the initiation of GnP, $\mathrm{n}(\%)$ & $9(39 \%)$ & $54(65 \%)$ & $0.371^{b}$ \\
\hline Pretreatment history of pregabalin, $\mathrm{n}(\%)$ & $4(17 \%)$ & $4(49 \%)$ & $0.068^{b}$ \\
\hline \multicolumn{4}{|l|}{ CIPN severity with GnP therapy } \\
\hline CIPN (-), n (\%) & $4(17 \%)$ & $29(35 \%)$ & $0.716^{\mathrm{a}}$ \\
\hline Grade 1, n (\%) & $12(52 \%)$ & $29(35 \%)$ & \\
\hline Grade 2, n (\%) & $7(30 \%)$ & $17(21 \%)$ & \\
\hline Grade 3, n (\%) & $0(0 \%)$ & $7(9 \%)$ & \\
\hline
\end{tabular}

The severity of CIPN was evaluated based on the medical records of medical staff at the time of discontinuation of GnP therapy or at the time of cutoff GJG Goshajinkigan, CIPN Chemotherapy-induced peripheral neuropathy

a Mann-Whitney $U$-test, ${ }^{\text {b }}$ Fisher's exact test

${ }^{\mathrm{C}}$ Median (minimum-maximum)

ILD improved in all cases in response to treatment early after onset.

Next, we examined candidate risk factors for ILD and identified the administration of goshajinkigan used for CIPN prevention as a risk factor. GJG is composed of Achyranthis Radix, Rehmanniae Radix, Dioscoreae Rhizoma, Corni Fructus, Alismatis Rhizoma, Plantaginis Semen, Moutan Cortex, Poria, Processi Aconiti Radix and Cinnamomi Cortex, and is used to treat dysuria, pollakiuria, edema, low back pain, etc. It is often used in the treatment of CIPN based on its putative peripheral blood flow-promoting and antinociception effects [12, 13]. There have been three case reports suggesting that GJG caused ILD [14-16]. Those cases showed no increase in $\mathrm{LDH}$ or $\mathrm{KL}-6$, and recovered in response to steroid treatment after discontinuing GJG. In our study, an increase in KL-6 was observed in 6/10 cases, but all recovered with steroid treatment after discontinuation of GJG, in line with the previous reports. We found no relationship between the period of GJG administration and the severity of ILD. The reported period from initiation of Kampo medicines to the appearance of ILD varied from several hours to 1 year [17-19], and it was unclear whether the appearance of ILD is dose-dependent. It was proposed that the induction of ILD by Kampo medicines is due to allergic reactions (mainly type III and type IV) [20], but the mechanism remains to be fully established. There has been no previous report on the onset of ILD caused by the combination of anticancer drugs and Kampo medicines. However, the number of cases of ILD was small in the present study, so further studies are needed to clarify the situation. Interestingly, we found no significant correlation between ILD onset and previously reported risk factors [4-9] in this study, but this may be due to the limited number of cases and the small numbers of comorbidities such as lung cancer and lung disease and poor performance status.

CIPN is a painful side effect for patients, and nabPTX contained in GnP can induce CIPN. Cryotherapy and the use of frozen gloves have been reported as preventive measures for CIPN [21, 22]. Prophylactic administration of GJG has also been suggested, though its effectiveness is unclear [23-26]. In this study, we found no preventive effect of GJG against CIPN. Furthermore, meta-analysis has indicated that GJG does not reduce the severity of CIPN in patients with colorectal cancer and breast cancer $[27,28]$. In addition, the CIPN Management Guide of the Cancer Support Society states that administration of GJG is not recommended for the prevention of CIPN symptoms caused by oxaliplatin [29], although taxane drugs including nabPTX are not mentioned. Our results suggest that administration of GJG to prevent CIPN may not be desirable.

Limitations of this study include the small number of cases, reflecting the incidence rate of ILD, and therefore we could not perform multivariate analysis. In addition, unified regular respiratory symptom monitoring could not be performed due to the retrospective nature of the study. According to the Abraxane ${ }^{\odot}$ Proper Use Guidelines (Taiho Yakuhin Kogyo Co., Ltd., December 2019 Revised), regular interviews with patients about initial symptoms such as fever, cough, shortness of breath, and dyspnea, auscultation, inspections of chest X-rays and $\mathrm{CT}$, and clinical laboratory tests such as KL- 6 values are recommended for early detection of ILD during GnP therapy. It will be important to develop a unified 
evaluation system for early detection of ILD in the hospital. Prospective trials based on the objective evaluation of ILD are also desirable. Also, we cannot rule out the possibility of that ILD was induced by GJG in some patients. At present, the frequency of GJG-induced ILD is unknown and there are only three reports of GJGinduced ILD to date. Finally, we could not confirm patients' compliance with the prescribed GJG treatment during outpatient visits.

In conclusion, the incidence of ILD in PDAC patients treated with GnP therapy at our hospital was $9.5 \%$, and coadministration of GJG appeared to be a risk factor for ILD. In addition, we found that preventive administration of GJG does not reduce the severity of CIPN. There is still no clear evidence that GJG can prevent CIPN, so GJG administration may need to be reconsidered, and in any event respiratory symptoms should be carefully monitored.

\section{Acknowledgements}

Not applicable.

\section{Authors' contributions}

$\mathrm{RU}$ conceived the study, designed the protocol, carried out the study, and drafted the manuscript. RU collected data from clinical records. NY, YH, KY, $\mathrm{KO}, \mathrm{T}, \mathrm{TS}$ and YS coordinated the study and helped draft the manuscript. $\mathrm{RU}$ wrote the paper. All authors revised the manuscript for intellectual content and approved the final manuscript.

\section{Funding}

Not applicable.

\section{Availability of data and materials}

All data generated or analyzed during this study are included in this published article.

\section{Declarations}

\section{Ethics approval and consent to participate}

This study was conducted with the approval of the Kanazawa University Medical Ethics Review Committee in compliance with the "Ethical Guidelines for Medical Research for Humans" (Clinical Trial No. 2018-151).

\section{Consent for publication}

Not applicable.

\section{Competing interests}

The authors declare that they have no competing interests.

\section{Author details}

${ }^{1}$ Department of Hospital Pharmacy, University Hospital, Kanazawa University, 13-1 Takaramachi, Kanazawa, Ishikawa, Japan. 'Division of Medical Oncology, Cancer Research Institute, Kanazawa University, 13-1 Takaramachi, Kanazawa, Ishikawa, Japan. ${ }^{3}$ Department of Gastroenterology, Graduate School of Medicine, Kanazawa University, 13-1 Takaramachi, Kanazawa, Ishikawa, Japan.

Received: 19 October 2021 Accepted: 13 December 2021

Published online: 02 February 2022

\section{References}

1. Committee JPCSPCPGR. Pancreatic cancer clinical practice guidelines 2019 edition. Tokyo: Kanahara Publishing; 2019. p. 223-239

2. Ogawa $Y$, Suzuki E, Mikata R, Yasui S, Abe M, lino Y, et al. Five cases of interstitial pneumonitis due to gemcitabine and nab-paclitaxel combination treatment in pancreatic cancer patients. Pancreas. 2018;47(7):e42-3. https:// doi.org/10.1097/MPA.0000000000001088.
3. Von Hoff DD, Ervin T, Arena FP, Chiorean EG, Infante J, Moore M, et al. Increased survival in pancreatic cancer with nab-paclitaxel plus gemcitabine. N Engl J Med. 2013;369(18):1691-703. https://doi.org/10.1056/NEJMoa13043 69.

4. Japan Respiratory Society. Guide for diagnosis and treatment of druginduced pulmonary disorders. 2nd ed. Tokyo: Japan Respiratory Society; 2018. p. 3-14.

5. Hamada T, Yasunaga H, Nakai Y, Isayama H, Matsui H, Fushimi K, et al. Interstitial lung disease associated with gemcitabine: a Japanese retrospective cohort study. Respirology. 2016;21 (2):338-43. https://doi.org/1 0.1111/resp.12665.

6. Furuse J, Gemma A, Ichikawa W, Okusaka T, Seki A, Ishii T. Postmarketing surveillance study of erlotinib plus gemcitabine for pancreatic cancer in Japan: POLARIS final analysis. Jpn J Clin Oncol. 2017;47(9):832-9. https://doi. org/10.1093/jjco/hyx075.

7. Umemura S, Yamase H, Suwaki T, Katoh T, Yano T, Shiote Y, et al. Interstitial lung disease associated with gemcitabine treatment in patients with nonsmall-cell lung cancer and pancreatic cancer. J Cancer Res Clin Oncol. 2011; 137(10):1469-75. https://doi.org/10.1007/s00432-011-1013-1.

8. Hotta K, Kiura K, Takigawa N, Yoshioka H, Harita S, Kuyama S, et al. Comparison of the incidence and pattern of interstitial lung disease during erlotinib and gefitinib treatment in Japanese patients with non-small cell lung cancer: the Okayama lung Cancer study group experience. J Thorac Oncol. 2010;5(2):179-84. https://doi.org/10.1097/JTO.0b013e3181ca12e0.

9. Gemma A, Kusumoto M, Kurihara Y, Masuda N, Banno S, Endo Y, et al. Interstitial lung disease onset and its risk factors in Japanese patients with ALK-positive NSCLC after treatment with crizotinib. J Thorac Oncol. 2019; 14(4):672-82. https://doi.org/10.1016/j.jtho.2018.11.022.

10. Takeda T, Sasaki T, Fukuda K, Mie T, Furukawa T, Yamada Y, et al. Risk factors for gemcitabine plus nab-paclitaxel-induced interstitial lung disease in pancreatic cancer patients. Int J Clin Oncol. 2021;26(3):543-51. https://doi. org/10.1007/s10147-020-01827-2.

11. Irie H, Suzuki R, Takagi T, Sugimoto M, Konno N, Sato Y, et al. Interstitial lung disease in advanced pancreatic ductal adenocarcinoma patients treated with gemcitabine and nab-paclitaxel combination therapy: a retrospective analysis. Cancer Chemother Pharmacol. 2020;85(3):517-23. https://doi.org/10.1007/s00280-019-03983-3.

12. Suzuki Y, Goto K, Ishige A, Komatsu Y, Kamei J. Antinociceptive effect of gosha-jinki-Gan, a Kampo medicine, in streptozotocin-induced diabetic mice. Jpn J Pharmacol. 1999;79(2):169-75. https://doi.org/10.1254/jip.79.169.

13. Suzuki Y, Goto K, Ishige A, Komatsu Y, Kamei J. Antinociceptive mechanism of gosha-jinki-Gan in streptozotocin-induced diabetic animals: role of nitric oxide in the periphery. Jpn J Pharmacol. 1999;79(3):387-91. https://doi.org/1 0.1254/jjp.79.387.

14. Katayama H, Hamada H, Yokoyama A, Kadowaki T, Ito R, Higaki J. A case of interstitial pneumonia caused by gosha-jinki-Gan. Jpn J Geriat. 2004;41(6): 675-8. https://doi.org/10.3143/geriatrics.41.675.

15. Matsushima H, Takayanagi N, Tokunaga D, Maeno Y, Miyaoka K, Sato N, et al. A case of gosha-jinki-Gan induced interstitial pneumonitis and the review of the literature. Nihon Kyobu Rinsho. 2003;62:363-8.

16. Okamura K, Sakamoto H, Takiguchi J, Hashimoto Y, Inoue N, Onishi K. A case of gosha-jinki-Gan induced interstitial pneumonitis. Nihon Kyobu Rinsho. 2012;71:172-7.

17. Nakagawa A, Yamaguchi T, Takao K, Amano Y. Five cases of drug-induced pneumonitis due to Sho-saiko-to or interferon-alpha or both. Nihon Kyobu Shikkan Gakkai Zasshi. 1995;33(12):1361-6.

18. Sato A, Toyosima M, Kondo A, Ota K, Sato H, Osumi A. Pneumonitis induced by the herbal medicine Sho-saiko-to in Japan. Nihon Kyobu Shikkan Gakkai Zasshi. 1997;35(4):391-5.

19. Hatakeyama S, Tachibana A, Morita M, Suzuki K, Okano H. Five cases of pneumonitis induced by sho-saiko-to. Nihon Kyobu Shikkan Gakkai Zasshi. 1997;35(5):505-10.

20. Honma S, Nakada K. Yakuzaiseihaien. Igakutoyakugaku. 1996;35:29-37.

21. Hanai A, Ishiguro H, Sozu T, Tsuda M, Yano I, Nakagawa T, et al. Effects of cryotherapy on objective and subjective symptoms of paclitaxel-induced neuropathy: prospective self-controlled trial. J Natl Cancer Inst. 2018;110(2): 141-8. https://doi.org/10.1093/jnci/djx178.

22. Sato J, Mori M, Nihei S, Kumagai M, Takeuchi S, Kashiwaba M, et al. The effectiveness of regional cooling for paclitaxel-induced peripheral neuropathy. J Pharm Health Care Sci. 2016;2(1):33. https://doi.org/10.1186/s4 0780-016-0067-2. 
23. Oki E, Emi Y, Kojima H, Higashijima J, Kato T, Miyake Y, et al. Preventive effect of Goshajinkigan on peripheral neurotoxicity of FOLFOX therapy (GENIUS trial): a placebo-controlled, double-blind, randomized phase III study. Int J Clin Oncol. 2015;20(4):767-75. https://doi.org/10.1007/s10147-01 5-0784-9.

24. Kono T, Hata T, Morita S, Munemoto Y, Matsui T, Kojima H, et al. Goshajinkigan oxaliplatin neurotoxicity evaluation (GONE): a phase 2, multicenter, randomized, double-blind, placebo-controlled trial of goshajinkigan to prevent oxaliplatin-induced neuropathy. Cancer Chemother Pharmacol. 2013;72(6):1283-90. https://doi.org/10.1007/s00280013-2306-7.

25. Nishioka M, Shimada M, Kurita N, Iwata T, Morimoto S, Yoshikawa K, et al. The Kampo medicine, Goshajinkigan, prevents neuropathy in patients treated by FOLFOX regimen. Int J Clin Oncol. 2011;16(4):322-7. https://doi. org/10.1007/s10147-010-0183-1.

26. Kaku H, Kumagai S, Onoue H, Takada A, Shoji T, Miura F, et al. Objective evaluation of the alleviating effects of Goshajinkigan on peripheral neuropathy induced by paclitaxel/carboplatin therapy: a multicenter collaborative study. Exp Ther Med. 2012;3(1):60-5. https://doi.org/10.3892/ etm.2011.375

27. Hoshino N, Ganeko R, Hida K, Sakai Y. Goshajinkigan for reducing chemotherapy-induced peripheral neuropathy: a systematic review and meta-analysis. Int J Clin Oncol. 2018;23(3):434-42. https://doi.org/10.1007/s1 0147-017-1229-4.

28. Kuriyama A, Endo K. Goshajinkigan for prevention of chemotherapy-induced peripheral neuropathy: a systematic review and meta-analysis. Support Care Cancer. 2018;26(4):1051-9. https://doi.org/10.1007/s00520-017-4028-6.

29. Japan Cancer Supportive Society. Guide to Management of Peripheral Neuropathy Associated with Cancer Pharmacotherapy, vol. 2017. Tokyo: Kanahara Publishing; 2017 Edition. p. 35-47.

\section{Publisher's Note}

Springer Nature remains neutral with regard to jurisdictional claims in published maps and institutional affiliations.

Ready to submit your research? Choose BMC and benefit from:

- fast, convenient online submission

- thorough peer review by experienced researchers in your field

- rapid publication on acceptance

- support for research data, including large and complex data types

- gold Open Access which fosters wider collaboration and increased citations

- maximum visibility for your research: over $100 \mathrm{M}$ website views per year

At $\mathrm{BMC}$, research is always in progress.

Learn more biomedcentral.com/submissions 